\title{
Schwannomin-Interacting Protein-1 Isoform IQCJ-SCHIP-1 Is a Late Component of Nodes of Ranvier and Axon Initial Segments
}

\author{
Pierre-Marie Martin, ${ }^{1,2,3}$ Michèle Carnaud, ${ }^{1,2,3}$ Gontzal Garcia del Caño, ${ }^{4,5,6}$ Marie Irondelle, ${ }^{4,5}$ Theano Irinopoulou, ${ }^{1,2,3}$ \\ Jean-Antoine Girault, ${ }^{1,2,3}$ Bénédicte Dargent, ${ }^{4,5}$ and Laurence Goutebroze ${ }^{1,2,3}$ \\ ${ }^{1}$ Unité Mixte de Recherche-S 839, Inserm, ${ }^{2}$ Université Pierre et Marie Curie (UPMC), ${ }^{3}$ Institut du Fer à Moulin, Paris 75005, France, ${ }^{4}$ U641, Inserm, \\ ${ }^{5}$ Université de la Méditerranée, Faculté de Médecine Secteur Nord, Institut Fédératif de Recherche 11, Marseille 13916, France, and ${ }^{6}$ Department of \\ Neurosciences, Faculty of Pharmacy, University of the Basque Country, Vitoria-Gasteiz, 01006 Araba, Spain
}

\begin{abstract}
Axon initial segments (AISs) and nodes of Ranvier (NRs) are essential regions for saltatory conduction of the action potential along the axon. These two domains are enriched in similar multimolecular complexes, which include voltage-gated sodium channels $\left(\mathrm{Na}_{\mathrm{v}}\right)$, NF186 (neurofascin 186), NrCAM (neuron glia-related cell adhesion molecule), and cytoskeleton linkers ankyrin G (AnkG) and $\beta$ IV-spectrin. Identification of novel members of these complexes is critical to better understand their formation, function, and maintenance. Here we report that IQCJ-SCHIP-1, a recently identified isoform of schwannomin-interacting protein-1 (SCHIP-1), is a novel component of both AISs and NRs in the central and peripheral nervous systems. We show that IQCJ-SCHIP-1 binds calmodulin in the absence of Ca ${ }^{2+}$ and is highly enriched at AISs and NRs. IQCJ-SCHIP-1 accumulation at AISs and NRs is a late event, suggesting that IQCJ-SCHIP-1 is likely to play a role in mature AISs and NRs rather than during their formation. IQCJ-SCHIP-1 was not detected at AISs in the absence of AnkG and interacted in vitro with this protein. IQCJ-SCHIP-1 was also absent from central NRs and AISs of quivering mice, which have a mutation of $\beta I V$-spectrin. We suggest that IQCJ-SCHIP-1 might participate, along with AnkG and $\beta I V$-spectrin, in the stabilization or function of the multimolecular complexes of AISs and NRs, possibly by participating in $\mathrm{Ca}^{2+}$-mediated responses.
\end{abstract}

Key words: myelinated fibers; schwannomin/merlin; calmodulin; ankyrin G; $\beta \mathrm{IV}$-spectrin; voltage-gated sodium channels; language disorder

\section{Introduction}

Saltatory electric conduction in myelinated axons depends on the compartmentalization of voltage-gated sodium channels $\left(\mathrm{Na}_{\mathrm{v}}\right)$ in two specialized axonal domains of the neuron: the axon initial segment (AIS) and the node of Ranvier (NR). $\mathrm{Na}_{\mathrm{v}}$ channels are part of multimolecular complexes, which are very similar in AISs and NRs, including transmembrane adhesion molecules of the Ig superfamily [neuron glia-related cell adhesion molecule (NrCAM) and neurofascin 186 (NF186)] and the cytoskeletalassociated proteins ankyrin $\mathrm{G}(\mathrm{AnkG})$ and $\beta \mathrm{IV}$-spectrin (Salzer, 2003). Physiological processes that specify NR and AIS formation

\footnotetext{
Received Nov. 8, 2007; revised April 17, 2008; accepted April 22, 2008.

This work was supported in part by grants from Association pour la Recherche sur la Sclérose en Plaques, National Multiple Sclerosis Society (RG 3535-A-1), Association Française contre les Myopathies (E111054A/S01334 and MNM2-2006-12207), Agence National pour la Recherche (ANR-05-NEUR-003-01 and ANR-05-NEUR-012-01), Association pour la Recherche sur le Cancer (7905), and Fondation pour la Recherche Médicale (DEQ20051205734). P.-M.M. and M.I. were the recipients of fellowships from Fondation pour la Recherche Médicale. P.-M.M. was supported by a Ministère de I'Enseignement supérieur et de la Recherche Fellowship; G.G.d.C. was supported by a Ministerio de Educación y Ciencia grant (PR2005-0136). We thank C. Diaz, G. Levasseur, M. Garcia, M.-C. Boutterin, and M. Monbureau for advice and assistance in some experiments. We are grateful to J. Devaux for $q v^{3 /}$ mice and V. Bennett for cerebellum-specific AnkG knock-out mice and Ank-MBD plasmid.

Correspondence should be addressed to Laurence Goutebroze and Jean-Antoine Girault at the above address. E-mail: goutebro@fer-a-moulin.inserm.fr and girault@fer-a-moulin.inserm.fr.

D0I:10.1523/JNEUROSCI.1044-08.2008

Copyright $\odot 2008$ Society for Neuroscience $\quad$ 0270-6474/08/286111-07\$15.00/0
}

and their initiation have been extensively investigated and are now beginning to be well understood.

Initiation of assembly of NR components strongly depends on NF186. In the peripheral nervous system (PNS), NF186 is recruited to the node by a Schwann cell protein, gliomedin (Eshed et al., 2005), and acts as a docking site for AnkG (Dzhashiashvili et al., 2007). The subsequent formation of NRs is critically dependent on AnkG (Dzhashiashvili et al., 2007), which serves as a protein scaffold to which both $\beta \mathrm{IV}$-spectrin and $\mathrm{Na}_{\mathrm{v}}$ bind (Lemaillet et al., 2003; Yang et al., 2007). AnkG also acts as a critical organizer of AISs (Zhou et al., 1998; Jenkins and Bennett, 2001; Pan et al., 2006; Hedstrom et al., 2007; Yang et al., 2007). However, unlike NRs, AISs are intrinsically specified, forming independently of glial signals (Catterall, 1981; Alessandri-Haber et al., 1999).

Less is known about the long-term stabilization of NRs and AISs, although $\beta I V$-spectrin, which is targeted to AISs after AnkG and NF186 (Jenkins and Bennett, 2001), has been proposed to play such a role (Lacas-Gervais et al., 2004; Yang et al., 2004, 2007). In "quivering" $q v^{3 J}$ mice, which are devoid of $\beta I V$-spectrin in the CNS, NRs are still able to form but are severely disorganized (Yang et al., 2004). Furthermore, AISs form normally in $q v^{3 J}$ mice but are destabilized with increasing age (Yang et al., 2007). The precise mechanisms governing the stabilization of the 
multimolecular complexes are not yet known, and a full understanding of these processes will require the identification and characterization of the proteins involved.

SCHIP-1 was identified in a yeast two-hybrid screen as a partner of the tumor suppressor protein schwannomin/merlin and is highly enriched in the brain (Goutebroze et al., 2000). Two isoforms resulting from alternative splicing were originally described, and more recently, another isoform containing an IQ motif (Bähler and Rhoads, 2002), IQCJ-SCHIP-1, has been reported as the product of a candidate gene for language disorder (Kwasnicka-Crawford et al., 2006). In this study, we identify IQCJ-SCHIP-1 as a novel component of AIS and NR multimolecular complexes and investigate its involvement in AIS and NR formation and maintenance. Our results suggest that IQCJSCHIP-1 is likely to play a role in mature AISs and NRs. We propose that IQCJ-SCHIP-1 might participate in long-term stabilization or function of AISs and NRs.

\section{Materials and Methods \\ Mutant mice \\ Cerebellum-specific AnkG knock-out (cs-AnkG-KO) mice (Zhou et al., 1998) and C57BL/6JSpn $4^{q v 3 J /+}$ mutant mice (Parkinson et al., 2001) were generous gifts from Prof. V. Bennett (Duke University Medical Center, Durham, NC) and J. Devaux (Centre National de la Recherche Scientifique, UMR6231 Marseilles, France), respectively. Two-month- old homozygous mice were analyzed.}

\section{Immunocytochemistry}

Immunostaining of cryostat sections $(10 \mu \mathrm{m})$ of rat and mouse tissues was performed as described previously (Goutebroze et al., 2003) using methanol/acetone fixation in all cases. Images were acquired using a Leica SP2 confocal laser-scanning microscope (Leica).

\section{Antibodies}

Rabbit antibody $\alpha 17141$ and chicken antibody $\alpha 964$ were described previously (Goutebroze et al., 2000). Antibodies $\alpha 16199$ and $\alpha 15013$ were obtained by immunizing rabbits with glutathione $S$-transferase (GST) fused to the first 22 aa of SCHIP-1a and SCHIP-1b (GST-a/b), and the first 97 aa of IQCJ-SCHIP-1 (GST-IQCJ), respectively. Commercial antibodies were from the following sources: $\mathrm{Na}_{\mathrm{v}} \alpha$-subunit, pan-specific mouse monoclonal antibody (mAb; clone K58/35), Sigma-Aldrich; Caspr/paranodin, mouse mAb (clone K65/35), Antibodies Incorporated; AnkG, mouse mAb (clone 463), EMD Biosciences; calmodulin, mouse $\mathrm{mAb}$, Millipore; MAP2 chicken polyclonal antibody, Abcam; green fluorescent protein (GFP), mouse mAb, Roche; GST, rabbit polyclonal antibody (gift from F. Castets, Inserm U641, Marseilles, France); secondary antibodies for immunocytochemistry (Alexa 488/546/633-conjugated), Invitrogen; IRDye800CW-conjugated donkey anti-rabbit and antimouse antibodies, Rockland Immunochemicals.

\section{Cell culture, immunoblotting, and immunofluorescence}

COS-7 cell transfection and immunoblotting were performed as described previously (Goutebroze et al., 2003). Primary hippocampal neurons were prepared from embryonic day 18 rats according to Goslin and Banker (1989), with slight modifications (Garrido et al., 2003). Cells were fixed in methanol during $10 \mathrm{~min}$ at $-20^{\circ} \mathrm{C}$ before incubation for $45 \mathrm{~min}$ in blocking buffer $(0.22 \%$ gelatin, $0.066 \%$ saponin, and $1 \%$ normal goat serum in phosphate buffer). Primary antibodies and secondary antibodies diluted in blocking buffer were applied for 60 and $45 \mathrm{~min}$, respectively. Coverslips were mounted in FluorSave reagent (EMD Biosciences).

\section{GST pull-down assays}

Interaction with calmodulin. Bovine calmodulin ( $5 \mu \mathrm{g}$; EMD Biosciences) was incubated with $5 \mu \mathrm{g}$ of GST-fusion proteins in $20 \mathrm{~mm}$ Tris $\mathrm{HCl}, \mathrm{pH}$ 8, $100 \mathrm{~mm} \mathrm{KCl}, 0.1 \mathrm{~mm}$ EDTA, 10\% glycerol, $5 \mathrm{~mm} \mathrm{MgCl}_{2}, 0.5 \mathrm{~mm}$ DTT, and $0.5 \% \mathrm{NP}-40$ containing either $2 \mathrm{mM} \mathrm{CaCl}_{2}$ or $2 \mathrm{~mm}$ EGTA.

Interaction with ankyrin. HEK293A cells transfected with GFPSCHIP-1 plasmids were lysed in $50 \mathrm{~mm}$ Tris- $\mathrm{HCl}, \mathrm{pH} 7.6,0.9 \% \mathrm{NaCl}$, and $1 \mathrm{~mm}$ EDTA, and solubilized with $1 \%$ Triton X-100. Lysates were incubated in this buffer with $5 \mu \mathrm{g}$ of GST-Ank-membrane-binding domain $[\mathrm{MBD}$; which contains the region of ANK repeats (residues 1-862) of human Ankyrin B].

For all pull-down experiments, mixtures were incubated at $4^{\circ} \mathrm{C}$ for $3 \mathrm{~h}$ with glutathione-agarose beads. Beads were washed with the respective buffer, and bound proteins were eluted in sample buffer at $100^{\circ} \mathrm{C}$ and separated by SDS-PAGE. Calmodulin and GFP-tagged proteins were detected by immunoblotting, and GST proteins visualized by Coomassie blue staining or anti-GST immunoblotting.

\section{Mouse SCHIP-1 isoform identification and cloning}

The sequences coding for the mouse homologues of the previously described human SCHIP-1 isoforms (Goutebroze et al., 2000; KwasnickaCrawford et al., 2006) were identified by screening the mouse genome and EST databases at NCBI using the basic local alignment search tool. The corresponding cDNAs were isolated by reverse transcription (RT)PCR experiments from mouse brain mRNA and sequenced. The cDNA sequences were deposited in GenBank (accession numbers: SCHIP-1a, EU163407; SCHIP-1b, EU163408; IQCJ-SCHIP-1, EU163409). For expression in COS-7 cells, the cDNAs were subcloned into the pcDNA3.1 vector (Invitrogen). For expression in E. coli, the appropriate cDNA fragments were subcloned in the pGEX-2T vector (GE Healthcare).

\section{Results}

\section{SCHIP-1 is a novel axonal component of AISs and NRs}

We previously demonstrated that SCHIP-1 is highly expressed in brain (Goutebroze et al., 2000). To determine its localization more precisely, we double immunolabeled mouse brain sections with $\alpha 17141$, a previously described antibody to SCHIP-1 (Fig. $1 A)$ (Goutebroze et al., 2000) and a pan-specific antibody to the $\alpha$-subunits of the sodium channel ( $\mathrm{panNa}_{\mathrm{v}}$ ). SCHIP-1 was highly enriched at the AISs in every observed population of neurons, including hippocampal neurons (Fig. $1 B$ ), Purkinje cells (supplemental Fig. $1 A$, available at www.jneurosci.org as supplemental material), and cortical neurons (supplemental Fig. $1 B$, available at www.jneurosci.org as supplemental material), perfectly overlapping with $\mathrm{Na}_{\mathrm{v}}$ staining. SCHIP-1 staining seemed to be evenly distributed throughout the entire AISs and was not detectable in the myelinated regions of the axon, the soma, or the dendrites. Throughout the entire brain, all $\mathrm{Na}_{\mathrm{v}}$-positive AISs were SCHIP-1 positive and vice versa.

We then examined the distribution of SCHIP-1 in PNS and CNS myelinated fibers. In longitudinal sections of sciatic nerves, SCHIP-1 immunoreactivity was detected at and restricted to NRs, overlapping with $\mathrm{Na}_{\mathrm{v}}$ staining (Fig. $1 C$, top). Sections perpendicular to the nerve axis further revealed that at NRs, SCHIP-1 localization was restricted to the periphery of the axon and was superimposed with $\mathrm{Na}_{\mathrm{v}}$ (Fig. 1C, bottom). On longitudinal sections of optic nerves, SCHIP-1 immunoreactivity was restricted to NRs, its position being easily identified by double labeling with antibodies to paranodin/Caspr, an axonal marker of the paranodal regions that flanks NRs (Menegoz et al., 1997) (Fig. $1 D)$. Coimmunostaining revealed a complete colocalization with $\mathrm{Na}_{\mathrm{v}}$ (Fig. $1 E$ ) on longitudinal and perpendicular sections (Fig. $1 E$, left and right insets, respectively). In both PNS and CNS, SCHIP-1 was detected in every NR identified by $\mathrm{Na}_{\mathrm{v}}$ or paranodin/Caspr staining. Conversely, no SCHIP-1-positive NR was negative for $\mathrm{Na}_{\mathrm{v}}$. Immunolabeling performed with another antibody directed against SCHIP-1, the previously described chicken polyclonal antibody $\alpha 964$ (Goutebroze et al., 2000), gave similar results (supplemental Fig. 2, available at www.jneurosci.org as supplemental material), demonstrating that SCHIP-1 is a novel component of AISs and NRs.

The presence of SCHIP-1 at both NRs and AISs in PNS and 
A
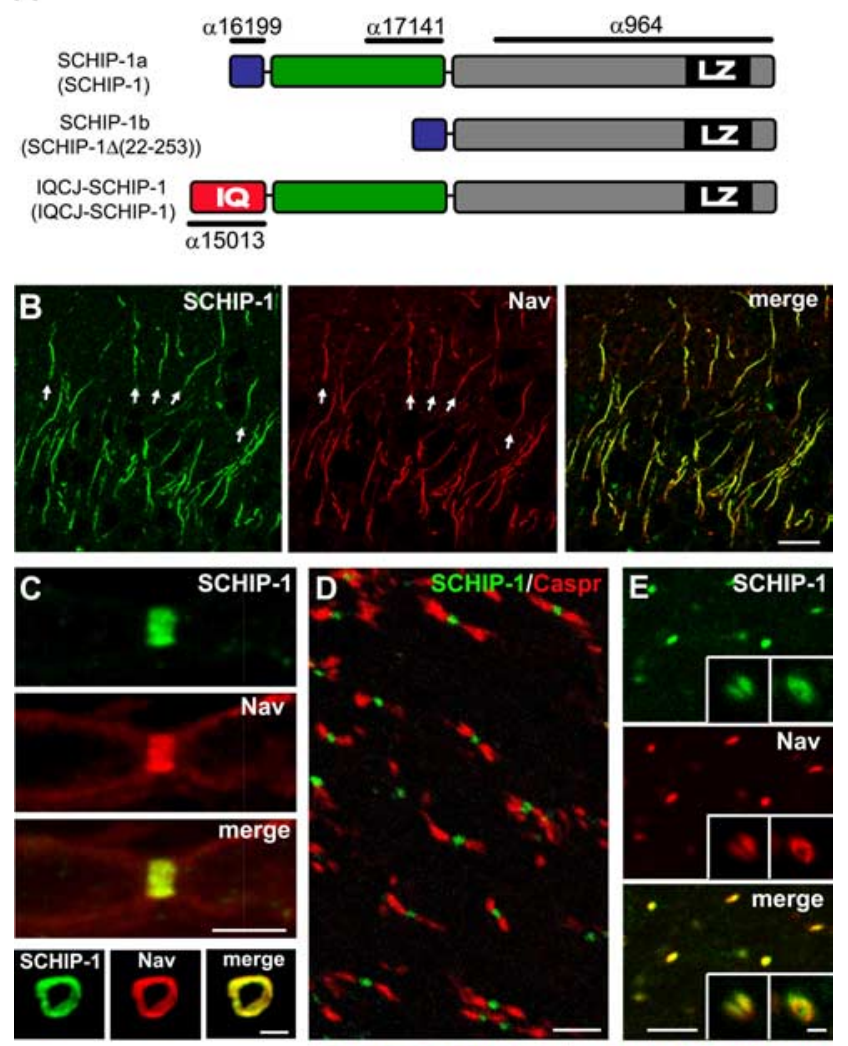

$\mathrm{F}$
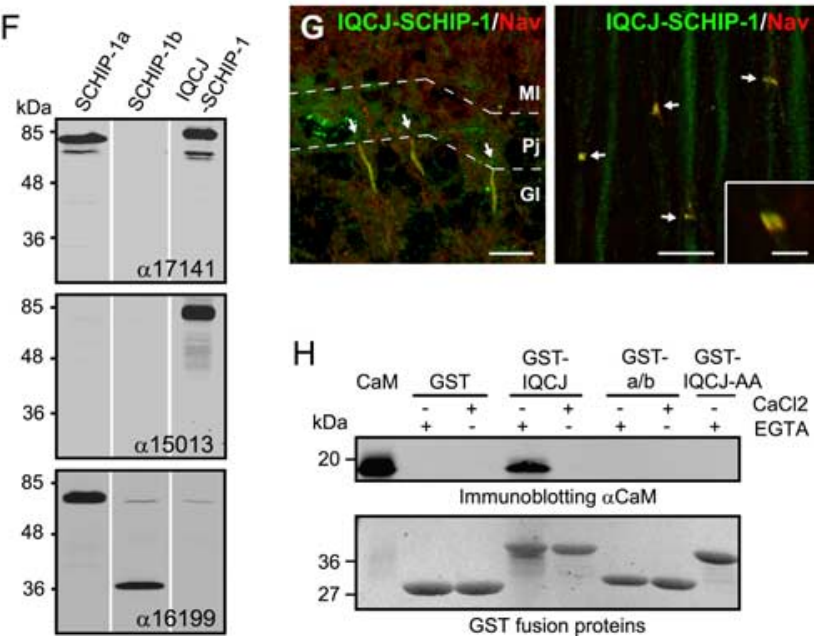

Figure 1. IQCJ-SCHIP-1 is concentrated at AISs and NRs. $\boldsymbol{A}$, Schematic representation of SCHIP-1 isoforms resulting from alternative splicing in mouse and human (names in human between parentheses). The three isoforms share a common (-terminal region (gray boxes), including a leucine zipper domain (black boxes; LZ). The N termini of SCHIP-1a and SCHIP-1b (blue boxes) are identical and differ from that of IQCJ-SCHIP-1, which includes an IQ motif (red box; IQ). IQCJ-SCHIP-1 and SCHIP-1a present an additional common central region (green boxes). The positions of the epitopes recognized by antibodies $\alpha 17141, \alpha 15013, \alpha 16199$, and $\alpha 964$ are indicated. $\boldsymbol{B}$, Sections of adult mouse brain double stained for SCHIP-1 ( $\alpha 17141$; green) and panNa $\mathrm{a}_{\mathrm{v}}$ (red). SCHIP-1 colocalizes with $\mathrm{Na}_{\mathrm{v}}$ at AISs (arrows) of hippocampal neurons. C, Sections of adult mouse sciatic nerves double stained for SCHIP-1 ( $\alpha 17141$; green) and $\operatorname{panNa}_{v}$ (red). Top, SCHIP-1 colocalizes with $\mathrm{Na}_{v}$ at NRs on longitudinal sections. Bottom, SCHIP-1 localization is restricted to the periphery of the axon and identical to $\mathrm{Na}_{\mathrm{v}}$ localization on transverse sections. $\boldsymbol{D}, \boldsymbol{E}$, Longitudinal sections of adult mouse optic nerves double stained for SCHIP-1 ( $\alpha 17141$; green) and paranodin/Caspr (D; red) or panNa $(\boldsymbol{E}$; red). SCHIP-1 is localized at every NR identified by paranodin/Caspr (D) or $\mathrm{Na}_{\mathrm{v}}$ staining $(\boldsymbol{E})$. $\boldsymbol{E}$, Insets, Higher magnification of single NR (left inset, longitudinal section; right inset, transversal section). $\boldsymbol{F}$, Specificity of $\alpha 17141, \alpha 15013$, and $\alpha 16199$ antibodies tested by immunoblotting on lysates of COS-7 cells overexpressing one of the three mouse isoforms of SCHIP-1, as indicated. G, Double immunolabeling of adult mouse cerebellum and sciatic nerve using antibodies to IQCJ-SCHIP-1
CNS suggests that it is located in the axon, as are the other proteins enriched at both NRs and AISs, i.e., AnkG, $\beta$ IV-spectrin, $\mathrm{Na}_{\mathrm{v}}, \mathrm{NrCAM}$, and NF186. Moreover, careful examination of transverse sections of sciatic nerve stained with SCHIP- 1 and $\mathrm{Na}_{\mathrm{v}}$ antibodies revealed that SCHIP-1 staining precisely overlapped with $\mathrm{Na}_{\mathrm{v}}$ staining, never surrounding it. In contrast, the immunofluorescence of glial proteins, including gliomedin, ERM (ezrin-radixin-moesin), or syndecans, forms a ring surrounding $\mathrm{Na}_{\mathrm{v}}$ immunoreactivity (Melendez-Vasquez et al., 2001; Goutebroze et al., 2003; Eshed et al., 2005).

\section{IQCJ-SCHIP-1, an isoform of SCHIP-1 that binds calmodulin, is enriched at AISs and NRs}

Three different isoforms of SCHIP-1 have been described in human (Goutebroze et al., 2000; Kwasnicka-Crawford et al., 2006). Using a combination of database mining and RT-PCR experiments, we demonstrated that these three isoforms were also expressed in mouse brain (Fig. 1A). We used COS-7 cells overexpressing each of these isoforms to characterize our antibodies. Antibody $\alpha 17141$ used above for immunolabeling detected SCHIP-1a and IQCJ-SCHIP-1 by immunoblotting (Fig. $1 F$ ). To determine which of these two isoforms were enriched at AISs and/or NRs, we raised rabbit antibodies against the distinct $\mathrm{N}$-terminal regions of IQCJ-SCHIP-1 ( $\alpha 15013)$ and of SCHIP-1a ( $\alpha 16199$ ) (Fig. 1A). Both $\alpha 15013$ and $\alpha 16199$ were selective for their cognate antigens, as determined by immunoblotting (Fig. $1 F)$ and immunofluorescence (data not shown) in transfected COS-7 cells. Double labeling with $\alpha 15013$ and $\mathrm{panNa}_{\mathrm{v}}$ antibodies revealed that IQCJ-SCHIP-1 was highly enriched at AISs and NRs in PNS (Fig. 1G) and CNS (data not shown) of adult mice. In contrast, staining was not detectable at AISs or NRs with $\alpha 16199$ throughout development, nor in the adult (data not shown), indicating that SCHIP-1a and SCHIP-1b are not localized at AISs and NRs, or are expressed below the antibody detection threshold. Thus, IQCJ-SCHIP-1 appears to be the major, if not the only, isoform of SCHIP-1 at NRs and AISs.

IQCJ-SCHIP-1 N-terminal region encompasses a consensus IQ motif, which has been shown to mediate the association of many proteins with calmodulin (Bähler and Rhoads, 2002) (Fig. $1 A$ ). We investigated the ability of the IQ motif of IQCJ-SCHIP-1 to associate with calmodulin by performing GST pull-down experiments. A GST fusion protein expressing the N-terminal region of IQCJ-SCHIP-1 (GST-IQCJ) precipitated calmodulin only in the absence of $\mathrm{Ca}^{2+}$ (Fig. $1 \mathrm{H}$ ). In contrast, calmodulin was not precipitated when the IQ residues were mutated to alanine (GST-IQCJ-AA) or when the experiments were performed with a GST fusion protein expressing the $\mathrm{N}$-terminal region of SCHIP-1a and SCHIP-1b, which does not contain an IQ motif (GST-a/b). These observations show that IQCJ-SCHIP-1 can interact with calmodulin in the absence of $\mathrm{Ca}^{2+}$.

( $\alpha 15013$; green) and panNa (red). IQCJ-SCHIP-1 is detectable at AISs and NRs (arrows). Inset, Higher magnification. $\boldsymbol{H}$, Ability of IQCJ-SCHIP-1 to interact with calmodulin (CaM), as determined by GST pull-down experiments. In absence of $\mathrm{Ca}^{2+}{ }^{2+}, \mathrm{CaM}$ is immunoprecipitated by a GST fusion protein expressing the N-terminal region IQCJ-SCHIP-1 (GST-IQCJ), but not by a GST fusion protein in which the IQ residues are mutated to alanine (GST-IQCJ-AA), or by a GST fusion protein expressing the N-terminal region of SCHIP-1a/b (GST-a/b). An aliquot ( $250 \mathrm{ng}$ ) of $\mathrm{CaM}$ was loaded on the same gel. Scale bars: $\boldsymbol{B}, \boldsymbol{G}, 10 \mu \mathrm{m} ; \boldsymbol{C}$ (top), $\mathbf{D}, \boldsymbol{E}, \boldsymbol{G}$ (inset), $5 \mu \mathrm{m} ; \boldsymbol{C}$ (bottom), $\boldsymbol{E}$ (insets), $1 \mu \mathrm{m}$. Gl, Granular layer; Pj, Purkinje cell layer; Ml, molecular layer. 
IQCJ-SCHIP-1 accumulation at NRs and AISs occurs after their formation To evaluate the possible role of IQCJSCHIP-1 in the formation of NRs, we compared the timing of IQCJ-SCHIP-1 accumulation with that of other molecular markers. We examined the distribution of IQCJ-SCHIP-1 and $\mathrm{Na}_{\mathrm{v}}$ during the development of sciatic nerves in rat pups from postnatal days 0 to 6 (P0 to $\mathrm{P} 6$ ). At $\mathrm{P} 6, \mathrm{Na}_{\mathrm{v}}$ and IQCJ-SCHIP-1 immunoreactivities were always associated (data not shown). In contrast, at P0, IQCJ-SCHIP-1 immunoreactivity was only identifiable in very few NRs detectable by $\mathrm{Na}_{\mathrm{v}}$ clusters (Fig. $2 A$, arrowhead), and was not detected in the large majority of them (Fig. $2 A$, arrows). IQCJ-SCHIP-1 staining was also absent from almost every NR in formation (heminodes) (Fig. $2 \mathrm{~A}$, insets). In addition, no IQCJ-SCHIP-1-positive NR was negative for $\mathrm{Na}_{\mathrm{v}}$. A similar developmental pattern of IQCJ-SCHIP-1 expression was observed in NRs of optic nerves (data not shown). Similar results were obtained with antibodies $\alpha 17141, \alpha 964$, and $\alpha 15013$. Thus, IQCJ-SCHIP-1 seems to accumulate in $\mathrm{NRs}$ after $\mathrm{Na}_{\mathrm{v}}$.

To characterize the accumulation of IQCJ-SCHIP-1 at AISs, we used cultured hippocampal neurons, which have the intrinsic ability to form AISs (Winckler et al., 1999) detectable by simultaneous accumulation of AnkG and $\mathrm{Na}_{\mathrm{v}}$ (Garrido et al., 2003). In mature hippocampal neurons in culture [day in vitro 23 (DIV 23)], IQCJ-SCHIP-1 immunostaining was highly concentrated at AISs identified by AnkG staining, whereas no signal was observed throughout the dendrites, visualized by MAP2 staining, and in the distal part of the axon (Fig. 2 B). We compared the time course of IQCJ-SCHIP-1 and AnkG accumulation by quantifying the percentage of hippocampal neurons displaying a positive signal for AnkG or IQCJ-SCHIP-1 at AISs at various stages of maturation between DIV 2 and DIV 24 (Fig. 2C). The percentage of AnkG-positive cells dramatically increased with time, as reported previously (Yang et al., 2007). The number of IQCJ-SCHIP-1positive AISs also increased with maturation time, but the time course of this increase was delayed compared with AnkG. The proportion of IQCJ-SCHIP-1-positive neurons was clearly lower than the number of AnkG-positive neurons at early stages of maturation (Fig. 2C). Importantly, all IQCJ-SCHIP-1-positive AISs were positive for AnkG. These results show that the accumulation of AnkG at the AISs precedes IQCJ-SCHIP-1 concentration in cultured hippocampal neurons.

\section{IQCJ-SCHIP-1 localization at AISs is lost in the absence of AnkG}

Together, our results demonstrating the enrichment of IQCJSCHIP-1 in both AISs and NRs raised the possibility that IQCJSCHIP-1 could be associated with the multimolecular complexes localized in these axonal domains. To investigate this hypothesis, we examined the distribution of IQCJ-SCHIP-1 at AISs of Purkinje cells of mice in which AnkG is not expressed in the cerebellum (cs-AnkG-KO mice) (Zhou et al., 1998). In these mice, the deficiency of AnkG prevents the enrichment of all the molecular components of AIS complexes in Purkinje cells (Zhou et al., 1998; Jenkins and Bennett, 2001; Komada and Soriano, 2002; Pan et al., 2006). This was also the case for IQCJ-SCHIP-1: IQCJ-SCHIP-1 immunoreactivity was not detectable at AISs of Purkinje cells in cs-AnkG-KO mice (Fig. 3B), whereas it was clearly detectable in wild-type mice (Fig. 3A). In contrast, IQCJ-SCHIP-1 staining was maintained in the mutant mice in other brain regions, such as cerebral cortex, where AnkG was not disrupted (Fig. 3C). These results demonstrate that the correct localization of IQCJSCHIP-1 at AISs is dependent on AnkG expression. To test whether IQCJ-SCHIP-1 can interact directly with AnkG, we performed GST pull-down assays. A GST-fusion protein expressing the conserved membrane binding domain of ankyrins (GSTAnk-MBD) precipitated GFP fused to SCHIP-1 but not to truncated SCHIP-1 lacking its C-terminal region (GFP-SCHIP$1 \Delta 414$ and GFP-SCHIP-1 $\Delta 307$ ) (Fig. $3 D, E$ ). These results suggest that an interaction between the MBD domain of AnkG and the C-terminal part of IQCJ-SCHIP-1 participates in the localization of IQCJ-SCHIP-1 at AISs and NRs.

\section{Accumulation of IQCJ-SCHIP-1 at AISs and NRs is altered in} $\boldsymbol{\beta I V}$-spectrin mutant mice $\left(\boldsymbol{q} \boldsymbol{v}^{3 J}\right)$

To further investigate the molecular mechanisms underlying the association of IQCJ-SCHIP-1 with the multimolecular complexes at AISs and NRs, we examined the distribution of IQCJSCHIP-1 in quivering $q v^{3 J}$ mice. These mice carry a spontaneous point mutation in the $\beta I V$-spectrin gene (Parkinson et al., 2001) that results in a dramatic decrease of $\beta \mathrm{IV}$-spectrin accumulation 

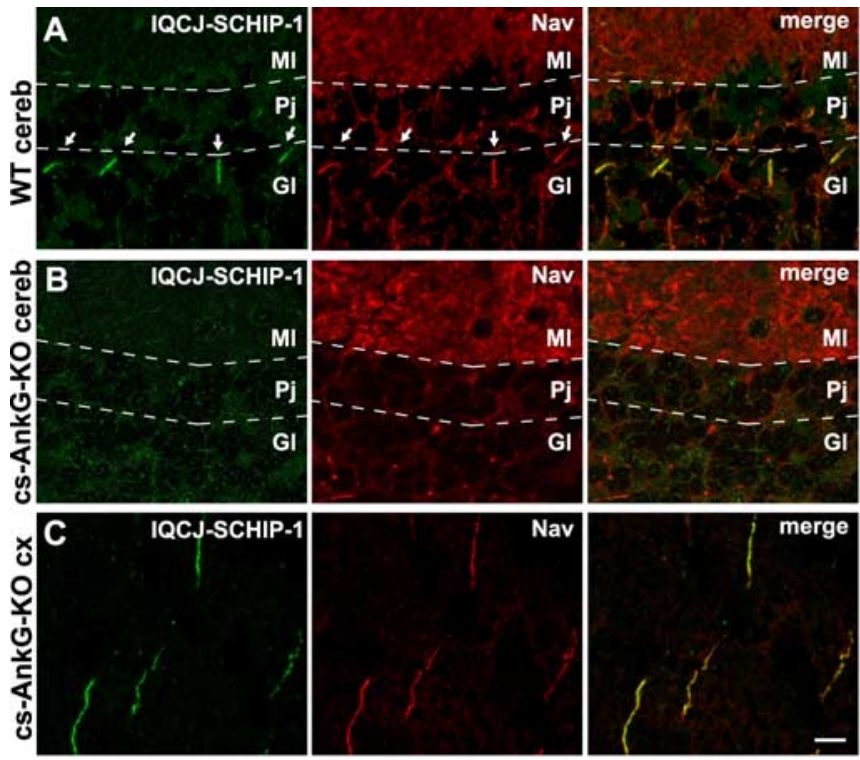

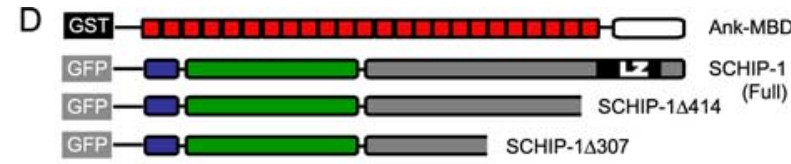

E GST pull-down GST-Ank-MBD pull-down Input

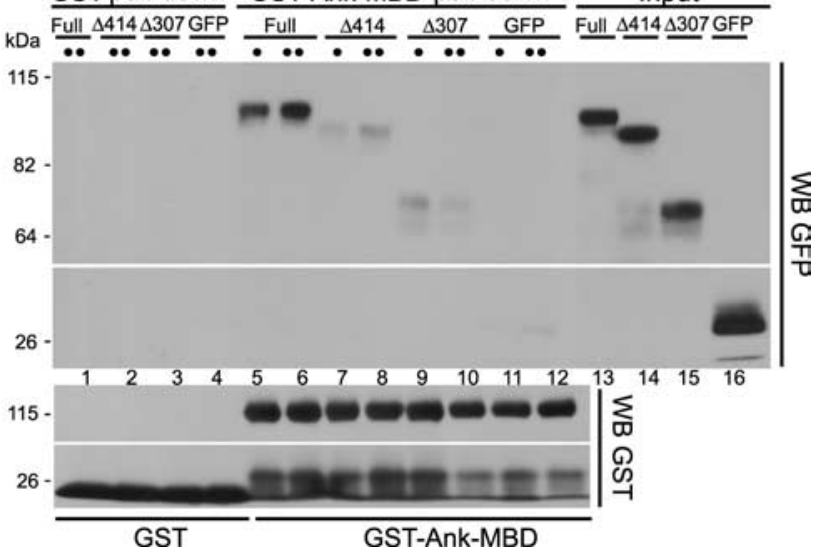

Figure 3. IQCJ-SCHIP-1 localization at AISs of Purkinje cells is lost in cerebellum-specific AnkG knock-out mice. $\boldsymbol{A}-\boldsymbol{C}$, Brain sections of wild-type ( $\boldsymbol{A}$; WT) and cerebellum-specific AnkG knock-out ( $\boldsymbol{B}, \boldsymbol{C}$; cs-AnkG-KO) mice double stained with $\alpha 17141$ (green) and panNa $($ red). $\boldsymbol{A}, \boldsymbol{B}$, IQCJ-SCHIP-1 and Na are not detectable at AISs of Purkinje cells of mutant mice (B), in contrast with wild-type mice ( $\boldsymbol{A}$, arrows). $\boldsymbol{C}$, IQCJ-SCHIP-1 and Nav labeling is normal at AISs of cortical neurons in cs-AnkG-KO mice. $\boldsymbol{D}$, Constructions used for GST pull-down experiments were as follows: GST-Ank-MBD includes the conserved MBD of ankyrins (red boxes). GFP-fusion proteins encompass SCHIP-1a (full) and SCHIP-1a $\Delta 414$ and SCHIP-1a $\Delta 307$ (deleted of the 73 and 180 C-terminal residues, respectively). E, GST-Ank-MBD (lanes 5-12), but not GST alone (lanes 1-4), precipitated GFP-SCHIP-1 (full; lanes 5-6) but not the truncated forms (lanes 7-10), nor GFP alone (lanes 11-12). For

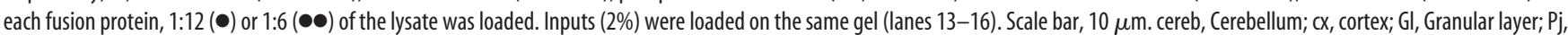
Purkinje cell layer; MI, molecular layer.

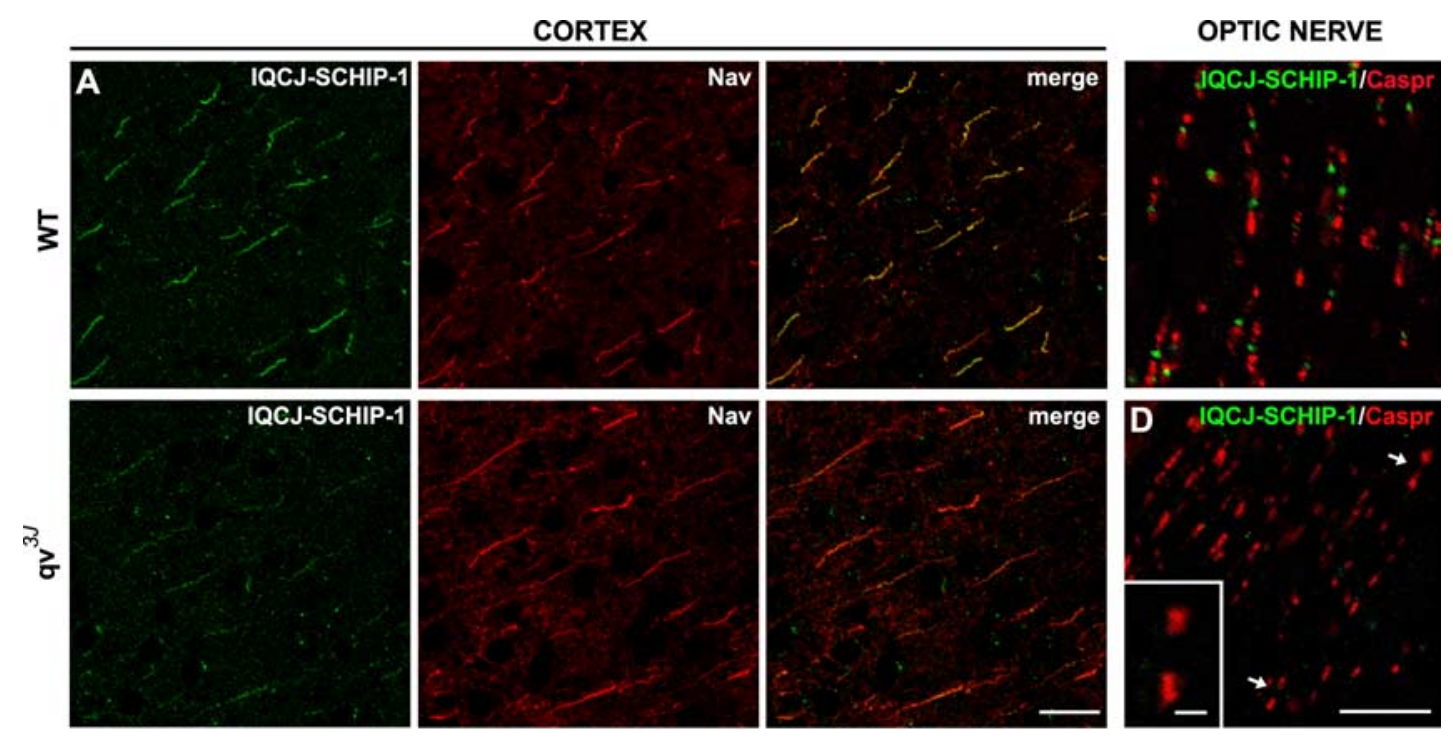

Figure 4. Clustering of IQCJ-SCHIP-1 at NRs and AISs is disrupted in $q v^{3 J}$ mice. $\boldsymbol{A}, \boldsymbol{B}$, Sections of brains of wild-type $(\boldsymbol{A} ; \mathrm{WT})$ and $q v^{3 J}\left(\boldsymbol{B} ; q v^{3}\right)$ mice double stained with $\alpha 17141$ (green) and panNa (red). IQCJ-SCHIP-1 staining at AISs of cortical neurons is dramatically reduced in 2-month-old $q v^{3 J}$ mice $(\boldsymbol{B})$ compared with wild-type mice $(\boldsymbol{A})$, whereas $\mathrm{Na}_{v}$ staining was unchanged. Quantification of immunofluorescence ( $t$ test) was as follows: IQCJ-SCHIP-1, WT $=100.5 \pm 5.5$ arbitrary units (a.u.), $q v^{3 J}=50.1 \pm 3.5$ a.u., $p<0.001 ; \mathrm{Na}_{\mathrm{v}}, \mathrm{WT}=131.5 \pm 3.6$ a.u., $q v^{3 J}=146.3 \pm 6.6$ a.u. $p>0.05, n=20$ AlSs per phenotype. IQCJ-SCHIP-1 staining was completely lost at AISs of 6-month-old $q v^{33}$ mice (data not shown). C, $\boldsymbol{D}$, Longitudinal sections of optic nerves of wild-type (C; WT) and $q v^{3 J}\left(\boldsymbol{D} ; q v^{3 J}\right)$ mice double stained with $\alpha 17141$ (green) and paranodin/Caspr (red). IQCJ-SCHIP-1 is not detectable at NRs identified by paranodin/Caspr labeling in $q v^{3 J}$ mice $(\boldsymbol{D} ;$ arrows), whereas it is clearly detectable at NRs of wild-type mice (C). D, Inset, Higher magnification of NRs lacking IQCJ-SCHIP-1 staining. Scale bars: $A, B, 20 \mu \mathrm{m} ; \boldsymbol{C}, \boldsymbol{D}, 10 \mu \mathrm{m} ; \boldsymbol{D}$, Inset, $2 \mu \mathrm{m}$.

at AISs and NRs. In the CNS, this leads to nodal disorganization, including elongation and enlargement (Yang et al., 2004). By performing double labeling with antibodies to $\mathrm{Na}_{\mathrm{v}}$, we found that IQCJ-SCHIP-1 immunostaining was markedly reduced at AISs of $q v^{3 J}$ mice central neurons, including cortical neurons, compared with wild-type mice (Fig. 4A,B). Moreover, we observed that IQCJ-SCHIP-1 accumulation was lost or dramatically reduced in all optic nerve NRs of the mutant mice, compared with wild-type mice (Fig. $4 C, D$; supplemental Fig. $3 A, B$, available at www.jneurosci.org as supplemental material). At PNS nodes, where $\beta I V$-spectrin disruption is less severe than in the CNS (Yang et al., 2004), IQCJ-SCHIP-1 nodal enrichment was lost at 6 months (supplemental Fig. 4, available at www.jneurosci.org as supplemental material), although it could be occasionally detected at 2 months (data not shown). Yang et al. (2004, 2007) showed that CNS AISs and NRs of $q v^{35}$ mice lack detectable $\beta I V-$ 
spectrin, whereas clustering of other components, including $\mathrm{Na}_{\mathrm{v}}$ and AnkG, is relatively maintained. Therefore, our observations indicate that the accumulation of IQCJ-SCHIP-1 is dependent on the presence of $\beta \mathrm{IV}$-spectrin.

\section{Discussion}

Our results show that IQCJ-SCHIP-1 is a previously unidentified component of AISs and NRs. Thus, it is part of a small group of proteins specifically enriched in these two functionally critical regions of the axon, which includes cell adhesion molecules $\mathrm{Nr}$ CAM and NF186 (Davis et al., 1996), voltage-gated sodium channels (Caldwell et al., 2000; Boiko et al., 2001; Jenkins and Bennett, 2001), and cytoskeleton-associated proteins AnkG (Kordeli et al., 1995) and $\beta I V$-spectrin (Berghs et al., 2000). These proteins are all components of AISs and NRs in both the central and peripheral nervous systems and are thus likely to be the core of functionally important multimolecular complexes. Indeed, several studies indicate that they are physically associated (Ratcliffe et al., 2001; Lemaillet et al., 2003; Pan et al., 2006; Yang et al., 2007). Moreover, their accumulation is dependent on each other. AnkG is a central player in all cases, but the mechanisms are different in AISs and NRs. At AISs, AnkG appears to play the initial role, and its targeting depends on intracellular determinants (Zhou et al., 1998; Dzhashiashvili et al., 2007). In contrast, the interaction of NF186 with glial partners is the initial step in NR formation, allowing the recruitment of AnkG (Sherman et al., 2005; Eshed et al., 2005; Dzhashiashvili et al., 2007). Our results show that IQCJSCHIP-1 interacts directly with AnkG, which is necessary for the targeting of IQCJ-SCHIP-1 to AISs. However, it is not clear whether Ank $G$ is sufficient for the accumulation of IQCJSCHIP-1 at NRs, because we found that this protein did not accumulate at CNS NRs of $q v^{3 J}$ mice, which lack detectable $\beta$ IVspectrin but not the other components (Yang et al., 2004). This result suggests that the accumulation of IQCJ-SCHIP-1 is also dependent on the presence of $\beta \mathrm{IV}$-spectrin. Further work will be required to determine whether IQCJ-SCHIP-1 interacts directly with $\beta \mathrm{IV}$-spectrin and the role of this hypothetical interaction in its targeting to NRs and AISs.

Developmental studies indicated that IQCJ-SCHIP-1 clustering at NRs and AISs occurs after $\mathrm{Na}_{\mathrm{v}}$, which is among the last proteins to accumulate in these regions. The other proteins of the complex accumulate earlier at AISs and NRs (Jenkins and Bennett, 2001, 2002). The late accumulation of IQCJ-SCHIP-1 at NRs and AISs suggests that it plays a role in mature NRs and AISs rather than during their formation. Therefore it may be speculated that IQCJ-SCHIP-1 participates in long-term stabilization and/or regulates functions of multimolecular complexes associated with $\mathrm{Na}_{\mathrm{v}}$ channels in the axonal membrane at AISs and NRs.

The finding that IQCJ-SCHIP-1 interacts with calmodulin in the absence of $\mathrm{Ca}^{2+}$ suggests that it could be involved in $\mathrm{Ca}^{2+}$ signaling. IQCJ-SCHIP-1 could be the target of $\mathrm{Ca}^{2+}$ effects if the release of bound calmodulin alters its functional properties or its interactions. Alternatively, IQCJ-SCHIP-1 could store calmodulin in AISs and NRs. Interestingly, although the role of $\mathrm{Ca}^{2+}$ at NRs has not been extensively studied, $\mathrm{Ca}^{2+}$-ATPase, $\mathrm{Ca}^{2+} / \mathrm{Na}^{+}$ exchanger, and IP3R are enriched in these regions, suggesting that changes in cytosolic $\mathrm{Ca}^{2+}$ play a functional role. Moreover, the function of several nodal proteins has been shown to be regulated by binding of $\mathrm{Ca}^{2+}$ and/or calmodulin. For example, calmodulin modifies the inactivation kinetics of nodal $\mathrm{Na}_{\mathrm{v}}(\mathrm{Herzog}$ et al., 2003) and inhibits the M-like current mediated by KCNQ2 (Gamper and Shapiro, 2003). Therefore, IQCJ-SCHIP-1 could provide a pool of calmodulin, available for the regulation of nodal channels.

IQCJ-SCHIP-1 could also participate in the stabilization of multimolecular complexes associated with $\mathrm{Na}_{\mathrm{v}}$ channels in the axonal membrane at AISs and NRs. In line with this idea, $\beta I V-$ spectrin is now thought to participate in the long-term stabilization of AISs and NRs rather than in their formation. Elimination of $\beta$ IV-spectrin expression by RNA interference does not prevent the other components from initially accumulating at AISs (Hedstrom et al., 2007; Dzhashiashvili et al., 2007), whereas NRs are formed in the PNS of $\beta$ IV-spectrin-null mice, albeit in decreased numbers (Komada et al., 2002). Moreover, the decreased staining of AnkG and $\mathrm{Na}_{\mathrm{v}}$ observed in AISs and NRs of $q v^{3 J}$ mice accentuates with age (Yang et al., 2004, 2007). Interestingly, evidence that AnkG and $\beta$ IV-spectrin are not the only organizers of AISs and NRs was provided by Xu and Shrager (2005), who reported that disruption of $\mathrm{Na}_{\mathrm{v}}$ expression in vitro prevented the accumulation of AnkG, NF186, and NrCAM at AISs. These results indicate that a variety of protein-protein interactions may be necessary for the formation and/or stabilization of AISs and NRs. IQCJ-SCHIP-1 could also participate in the stabilization of AISs and NRs.

Finally, it is interesting to point out that IQCJ-SCHIP-1 could play a role in pathology. SCHIP1 gene is located in a genomic region that has been linked to autism (Auranen et al., 2003). Furthermore, a 3q25-29 inversion in the vicinity of SCHIP-1 gene associated with a significant diminution of IQCJ-SCHIP-1 expression was reported in a patient with language impairment. Other proteins located in myelinated fibers have also been linked to autism. Calmodulin-binding sequence of the nodal $\mathrm{Na}_{\mathrm{v}} 1.2$ was mutated in an autistic family (Weiss et al., 2003). More recently, three independent studies identified a series of functional variants in the CNTNAP2 gene, which codes for the paranodal protein Caspr2, implicating this gene as a cause of autism in the general population (Alarcón et al., 2008; Arking et al., 2008; Bakkaloglu et al., 2008). The localization of IQCJ-SCHIP-1 in the NR provides additional evidence that alteration of the nodal region of myelinated fibers may be involved in language and autism-spectrum disorders.

Our results show that IQCJ-SCHIP-1 is a novel component of AISs and NRs and that its enrichment in these regions is dependent on AnkG and $\beta I V$-spectrin. The ability of IQCJ-SCHIP-1 to interact with calmodulin in the absence of $\mathrm{Ca}^{2+}$ suggests that it may participate in $\mathrm{Ca}^{2+}$ signaling in these regions. Developmental studies indicated that IQCJ-SCHIP-1 clustering at NRs and AISs occurs after their formation, suggesting that IQCJ-SCHIP-1 plays a role in mature NRs and AISs, possibly in the long-term stabilization or function of multimolecular complexes associated with $\mathrm{Na}_{\mathrm{v}}$ channels in the axonal membrane.

\section{References}

Alarcón M, Abrahams BS, Stone JL, Duvall JA, Perederiy JV, Bomar JM, Sebat J, Wigler M, Martin CL, Ledbetter DH, Nelson SF, Cantor RM, Geschwind DH (2008) Linkage, association, and gene-expression analyses identify CNTNAP2 as an autism-susceptibility gene. Am J Hum Genet 82:150-159.

Alessandri-Haber N, Paillart C, Arsac C, Gola M, Couraud F, Crest M (1999) Specific distribution of sodium channels in axons of rat embryo spinal motoneurones. J Physiol (Lond) 518:203-214.

Arking DE, Cutler DJ, Brune CW, Teslovich TM, West K, Ikeda M, Rea A, Guy M, Lin S, Cook EH, Chakravarti A (2008) A common genetic variant in the neurexin superfamily member CNTNAP2 increases familial risk of autism. Am J Hum Genet 82:160-164.

Auranen M, Varilo T, Alen R, Vanhala R, Ayers K, Kempas E, Ylisaukko-Oja T, Peltonen L, Järvelä I (2003) Evidence for allelic association on chro- 
mosome 3q25-27 in families with autism spectrum disorders originating from a subisolate of Finland. Mol Psychiatry 8:879-884.

Bähler M, Rhoads A (2002) Calmodulin signaling via the IQ motif. FEBS Lett 513:107-113.

Bakkaloglu B, O’Roak BJ, Louvi A, Gupta AR, Abelson JF, Morgan TM, Chawarska K, Klin A, Ercan-Sencicek AG, Stillman AA, Tanriover G, Abrahams BS, Duvall JA, Robbins EM, Geschwind DH, Biederer T, Gunel M, Lifton RP, State MW (2008) Molecular cytogenetic analysis and resequencing of contactin associated protein-like 2 in autism spectrum disorders. Am J Hum Genet 82:165-173.

Berghs S, Aggujaro D, Dirkx Jr R, Maksimova E, Stabach P, Hermel JM, Zhang JP, Philbrick W, Slepnev V, Ort T, Solimena M (2000) betaIV spectrin, a new spectrin localized at axon initial segments and nodes of ranvier in the central and peripheral nervous system. J Cell Biol 151:9851002.

Boiko T, Rasband MN, Levinson SR, Caldwell JH, Mandel G, Trimmer JS, Matthews G (2001) Compact myelin dictates the differential targeting of two sodium channel isoforms in the same axon. Neuron 30:91-104.

Caldwell JH, Schaller KL, Lasher RS, Peles E, Levinson SR (2000) Sodium channel $\mathrm{Na}(\mathrm{v}) 1.6$ is localized at nodes of ranvier, dendrites, and synapses. Proc Natl Acad Sci USA 97:5616-5620.

Catterall WA (1981) Localization of sodium channels in cultured neural cells. J Neurosci 1:777-783.

Davis JQ, Lambert S, Bennett V (1996) Molecular composition of the node of Ranvier: identification of ankyrin-binding cell adhesion molecules neurofascin (mucin+/third FNIII domain-) and NrCAM at nodal axon segments. J Cell Biol 135:1355-1367.

Dzhashiashvili Y, Zhang Y, Galinska J, Lam I, Grumet M, Salzer JL (2007) Nodes of Ranvier and axon initial segments are ankyrin G-dependent domains that assemble by distinct mechanisms. J Cell Biol 177:857-870.

Eshed Y, Feinberg K, Poliak S, Sabanay H, Sarig-Nadir O, Spiegel I, Bermingham Jr JR, Peles E (2005) Gliomedin mediates Schwann cell-axon interaction and the molecular assembly of the nodes of Ranvier. Neuron 47:215-229.

Gamper N, Shapiro MS (2003) Calmodulin mediates Ca2+-dependent modulation of M-type K+ channels. J Gen Physiol 122:17-31.

Garrido JJ, Giraud P, Carlier E, Fernandes F, Moussif A, Fache MP, Debanne D, Dargent B (2003) A targeting motif involved in sodium channel clustering at the axonal initial segment. Science 300:2091-2094.

Goslin K, Banker G (1989) Experimental observations on the development of polarity by hippocampal neurons in culture. J Cell Biol 108:1507-1516.

Goutebroze L, Brault E, Muchardt C, Camonis J, Thomas G (2000) Cloning and characterization of SCHIP-1, a novel protein interacting specifically with spliced isoforms and naturally occurring mutant NF2 proteins. Mol Cell Biol 20:1699-1712.

Goutebroze L, Carnaud M, Denisenko N, Boutterin MC, Girault JA (2003) Syndecan-3 and syndecan- 4 are enriched in Schwann cell perinodal processes. BMC Neurosci 4:29.

Hedstrom KL, Xu X, Ogawa Y, Frischknecht R, Seidenbecher CI, Shrager P, Rasband MN (2007) Neurofascin assembles a specialized extracellular matrix at the axon initial segment. J Cell Biol 178:875-886.

Herzog RI, Liu C, Waxman SG, Cummins TR (2003) Calmodulin binds to the $\mathrm{C}$ terminus of sodium channels $\mathrm{Na}_{\mathrm{v}} 1.4$ and $\mathrm{Na}_{\mathrm{v}} 1.6$ and differentially modulates their functional properties. J Neurosci 23:8261-8270.

Jenkins SM, Bennett V (2001) Ankyrin-G coordinates assembly of the spectrin-based membrane skeleton, voltage-gated sodium channels, and L1 CAMs at Purkinje neuron initial segments. J Cell Biol 155:739-746.

Jenkins SM, Bennett V (2002) Developing nodes of Ranvier are defined by ankyrin-G clustering and are independent of paranodal axoglial adhesion. Proc Natl Acad Sci USA 99:2303-2308.

Komada M, Soriano P (2002) [Beta]IV-spectrin regulates sodium channel clustering through ankyrin-G at axon initial segments and nodes of Ranvier. J Cell Biol 156:337-348.
Kordeli E, Lambert S, Bennett V (1995) AnkyrinG. A new ankyrin gene with neural-specific isoforms localized at the axonal initial segment and node of Ranvier. J Biol Chem 270:2352-2359.

Kwasnicka-Crawford DA, Carson AR, Scherer SW (2006) IQCJ-SCHIP1, a novel fusion transcript encoding a calmodulin-binding IQ motif protein. Biochem Biophys Res Commun 350:890-899.

Lacas-Gervais S, Guo J, Strenzke N, Scarfone E, Kolpe M, Jahkel M, De Camilli P, Moser T, Rasband MN, Solimena M (2004) BetaIVSigmal spectrin stabilizes the nodes of Ranvier and axon initial segments. J Cell Biol 166:983-990.

Lemaillet G, Walker B, Lambert S (2003) Identification of a conserved ankyrin-binding motif in the family of sodium channel alpha subunits. J Biol Chem 278:27333-27339.

Martinez-Gomez A, Dent MA (2007) Expression of IP3 receptor isoforms at the nodes of Ranvier in rat sciatic nerve. NeuroReport 18:447-450.

Mata M, Fink DJ (1989) Ca++-ATPase in the central nervous system: an EM cytochemical study. J Histochem Cytochem 37:971-980.

Melendez-Vasquez CV, Rios JC, Zanazzi G, Lambert S, Bretscher A, Salzer JL (2001) Nodes of Ranvier form in association with ezrin-radixin-moesin (ERM)-positive Schwann cell processes. Proc Natl Acad Sci USA 98:1235-1240.

Menegoz M, Gaspar P, Le Bert M, Galvez T, Burgaya F, Palfrey C, Ezan P, Arnos F, Girault JA (1997) Paranodin, a glycoprotein of neuronal paranodal membranes. Neuron 19:319-331.

Pan Z, Kao T, Horvath Z, Lemos J, Sul JY, Cranstoun SD, Bennett V, Scherer SS, Cooper EC (2006) A common ankyrin-G-based mechanism retains KCNQ and NaV channels at electrically active domains of the axon. J Neurosci 26:2599-2613.

Parkinson NJ, Olsson CL, Hallows JL, McKee-Johnson J, Keogh BP, NobenTrauth K, Kujawa SG, Tempel BL (2001) Mutant beta-spectrin 4 causes auditory and motor neuropathies in quivering mice. Nat Genet 29:61-65.

Ratcliffe CF, Westenbroek RE, Curtis R, Catterall WA (2001) Sodium channel betal and beta3 subunits associate with neurofascin through their extracellular immunoglobulin-like domain. J Cell Biol 154:427-434.

Salzer JL (2003) Polarized domains of myelinated axons. Neuron 40:297-318.

Sherman DL, Tait S, Melrose S, Johnson R, Zonta B, Court FA, Macklin WB, Meek S, Smith AJ, Cottrell DF, Brophy PJ (2005) Neurofascins are required to establish axonal domains for saltatory conduction. Neuron 48: 737-742.

Steffensen I, Waxman SG, Mills L, Stys PK (1997) Immunolocalization of the $\mathrm{Na}(+)-\mathrm{Ca} 2+$ exchanger in mammalian myelinated axons. Brain Res 776:1-9.

Weiss LA, Escayg A, Kearney JA, Trudeau M, MacDonald BT, Mori M, Reichert J, Buxbaum JD, Meisler MH (2003) Sodium channels SCN1A, SCN2A and SCN3A in familial autism. Mol Psychiatry 8:186-194.

Winckler B, Forscher P, Mellman I (1999) A diffusion barrier maintains distribution of membrane proteins in polarized neurons. Nature 397:698-701.

Xu X, Shrager P (2005) Dependence of axon initial segment formation on $\mathrm{Na}^{+}$channel expression. J Neurosci Res 79:428-441.

Yang Y, Lacas-Gervais S, Morest DK, Solimena M, Rasband MN (2004) BetaIV spectrins are essential for membrane stability and the molecular organization of nodes of Ranvier. J Neurosci 24:7230-7240.

Yang Y, Ogawa Y, Hedstrom KL, Rasband MN (2007) betaIV spectrin is recruited to axon initial segments and nodes of Ranvier by ankyrinG. J Cell Biol 176:509-519.

Zhou D, Lambert S, Malen PL, Carpenter S, Boland LM, Bennett V (1998) AnkyrinG is required for clustering of voltage-gated $\mathrm{Na}$ channels at axon initial segments and for normal action potential firing. J Cell Biol 143: 1295-1304. 